\title{
Histopathogical study of dermatological lesions in HIV reactive patients
}

\author{
Goswami $D^{1}$, Rayal $\mathbf{A}^{2}$, Jadav $M^{3}$ \\ ${ }^{1}$ Dr. Divyesh Goswami, Associate Professor, ${ }^{2}$ Dr. Abhishek Raval, Assistant Professor, ${ }^{3}$ Dr. Manan Jadav, Assistant \\ Professor, all authors are affiliated with Department of Pathology, Dr. M. K. Shah Medical College and Research Centre, \\ Chandkheda, Ahmedabad, India.
}

Address for Correspondence: Dr. Divyesh Goswami, Email: rockki1234@gmail.com

\begin{abstract}
Background: Skin lesions are commonly encountered in HIV patients ( $>90 \%)$. Several skin diseases have proved to be sensitive and useful indicators of progression of HIV infection. Although these conditions may be seen in general healthy population, their occurrence in patients with acquired immunodeficiency syndrome is often atypical, more severe and explosive. Objective: The present study was carried out to categorize the prevalence of different skin lesions in HIV positive patients, their clinical and histopathological analysis and role of skin biopsy in their diagnosis. Materials and Methods: A total 60 known HIV positive patients with the symptomatic skin lesions were included and their histopathological and clinical correlation and biopsy were analyzed. Results: Maximum patients were between 31 and 40 years $(41.6 \%$ ). Papular lesions and dermatitis are the most common lesions seen in patients having CD4 count $>350$ and viral and fungal infections are most common lesions seen in patients having CD4 count $<350$. Out of 60 cases, 10 (16.6\%) show features of papular lesions (including Pruritic Papular eruptions, Psoriasis, Seborrhoic dermatitis, Scaly lesion, Eosinophilic folliculitis, Lichen planus), 8(13.3\%) show features of dermatitis (including Atopic Dermatitis, Ashy Dermatitis, Urticaria, hyperpigmented patch, Chronic Non-specific dermatitis), and 8 (13.3\%) show features of bacterial infections (including Chanchroid, Hansen, TBVC, Folliculitis, pustular lesion, lupus vulgaris, syphilis, pyoderma gangrenosum). Histopathological examination showed high sensitivity of $88.8 \%$ and specificity of $96.0 \%$ in diagnosis of papular lesions. Conclusions: Morphological pattern of skin lesions in HIV is often nondiagnostic. Histopathological correlation is therefore pivotal in the accurate diagnosis of many HIV induced skin diseases. The histopathological examination of such lesions helps in confirming the diagnosis as they have high sensitivity and specificity values.
\end{abstract}

Keywords: Human immunodeficiency virus, Biopsy, Skin lesions, Histopathological correlation

\section{Introduction}

HIV/AIDS has been emerged as modern pandemic in recent few years all over the world. Approximately 40 million people are currently living with HIV infection, and an estimated 25 million have died from this disease [1]. The current global situation continues to worsen with maximum number of cases occurring in Asia and Sub Saharan Africa [2]. The rapid emergence of disease has forced intensive debates regarding health care issues, sexual practices in the community, immigration policies and also as regards formation of new laws for the affected people [3]. It has become evident that the medical personnel will be required to face HIV positive

Manuscript received: $28^{\text {th }}$ March 2017

Reviewed: $8^{\text {th }}$ April 2017

Author Corrected: $17^{\text {th }}$ April 2017

Accepted for Publication: $24^{\text {th }}$ April 2017 patients and their problems in every day practice. Diseases of skin and mucous membranes are common clinical manifestations of acquired immunodeficiency syndrome (AIDS). Cutaneous disorders are not only associated with terminal immunodeficiency, but also occur throughout the course of human immunedeficiency virus (HIV) infection. More than $90 \%$ of patients develop skin lesions at some time during the disease. In some patients, skin is the first organ affected [4,5]. Skin diseases have proved to be sensitive and useful measures by which HIV progression can be monitored. Impaired skin immune system occurring early in HIV disease is believed to be responsible for the frequent occurrence of both infectious and noninfectious skin diseases even before the 
development of full blown HIV infection [6]. Although skin lesions may be seen in the general healthy population, their occurrence in HIV infected patients is often atypical and more severe, explosive, extensive or resistant to therapy. The unusual histology of some of the diseases in AIDS may contribute to misdiagnosis. Thus, proper histological diagnosis of skin manifestations is very important as it may serve as the earliest manifestation to suspect a case of HIV infection. Infectious agents can produce skin lesions even though the classic organ of involvement for that the agent does not include the skin. Thus it has become necessary to be well acquainted with the Pathophysiology and histopathology of various lesions seen in HIV seropositive patients.

Skin biopsies play a vital diagnostic role when different diseases present with clinically similar skin lesions. The diagnosis may need to be confirmed with histochemical and immune-histochemical stains, and/or molecular studies. Where indicated, additional biopsies for microbiological culture should always be recommended. The examination of multiple serial sections often proves invaluable. A diagnostic approach is given based on the predominant histological reaction pattern, with an emphasis on clinico-pathological correlation [4].

Considering the high prevalence of dermatological manifestations in HIV patients, this study was carried out to know the prevalence and types of dermatological manifestations in HIV patients and to evaluate the role of skin biopsy in their diagnosis.

\section{Methodology}

Study Design: This was a cross sectional observation study for histopathological analysis of skin lesions in HIV reactive patients.

Setting: The study was conducted in the dermatology department of a tertiary care centre during the period of November 2013 to October 2014. The study protocol was approved by the Institutional ethics committee and written informed consent was obtained from all the patients before enrolling them for the study.

Inclusion and Exclusion criteria: All the HIV seropositive patients with cutaneous lesions attending to the dermatology clinics of the institute were included in the study and skin biopsy of the lesion obtained in all the clinically unconfirmed cases after taking informed consent. Non-cooperative patients, seriously ill patients and patients with severe thrombocytopenia or other bleeding disorders were excluded from the study.

Method of collection of data: Pertinent clinical history like age, duration of the lesion, site of the lesion, significant family and personal history, history of associated diseases and any drug intake was taken and entered in the Performa. After detailed general and local examination, the site of the biopsy was selected. The selected patients consent was taken after explaining the details of the biopsy procedure. The biopsy is done on the lesion along with the surrounding area. The biopsy area is cleaned \& painted with an antiseptic solution and adequate amount of local anaesthetic (2\% lidocaine) is injected to the skin and subcutaneous tissue.

Biopsy Techniques: Punch biopsy is the standard procedure for obtaining samples of skin biopsy. It is important to select a proper site for biopsy. Biopsy is taken from the active lesion. A specimen obtained with a $4 \mathrm{~mm}$ biopsy punch is adequate for histological study. A 3-mm punch may be preferable for small lesions or biopsy from face for cosmetic reasons. After the skin specimen has been loosened with the biopsy punch instrument, it should be handled very gently and should not be grasped with forceps.

It should be gently squeezed out of its socket, or carefully spread with the syringe needle that was used for the injection of local anaesthetic. The biopsy specimen taken should be placed in a fixative immediately on removal from the patient to prevent autolysis.

It should not be allowed to dry, and the dermatologist should check the specimen bottle to ensure that the tissue has not adhered to the sides of the bottle or remained inside the punch machine.

As fixative $10 \%$ formalin can be used in almost all instances. The biopsy specimen provided should include history of previous biopsies, adequate clinical history and any special requests if required. The histopathologist's ability to render an accurate diagnosis often depends on the available clinical information.

Every specimen submitted to histologic diagnosis should be accompanied by detailed clinical information, including differential diagnosis. Clinicopathological 
correlation is the key to providing optimal patient care. Gross examination of the skin biopsy: The three dimensional size and shape of the skin biopsy was assessed including the circular or elliptical shape of the biopsy.

The entire skin biopsy was submitted for routine processing and embedded in paraffin wax. From each block, two sections were taken for routine haematoxylin and eosin staining and one for any special stain if required.
Detailed staining procedures are explained below:

$5 \mu \mathrm{m}$ thick paraffin sections of the skin biopsy were stained with haematoxylin and eosin. All the sections were examined under microscope. Pathological findings were noted at the level of epidermis, dermis and subcutis and were segregated into different histological patterns.

Statistical analysis was done using Microsoft excel sheet.

\section{Results}

A total 60 skin biopsies from HIV seropositive patients attending the dermatology clinics could be included for the analysis. Demographic details of the patients are shown in table 1. Highest number of patients was from the age group of 31 to 40 years $(41.6 \%)$ and males are more affected as compared to females. In the present study skin lesions were seen most commonly in the patients having CD4 count of 350-500.

In this study, most common skin lesion found in HIV seropositive patients were papular eruptions, dermatitis and bacterial infections. Out of 60 cases, $10(16.6 \%)$ show features of papular lesions, $8(13.3 \%)$ show features of dermatitis and $8(13.3 \%)$ show features of bacterial infections [Table 2]

Table-1: Demographic parameters of study patients: $(n=60)$.

\begin{tabular}{|c|c|}
\hline Parameter & Number (\%) \\
\hline Age in years & $20(33.3)$ \\
\hline $21-30$ & 25 \\
\hline $31-40$ & 11 \\
\hline $41-50$ & 4 \\
\hline $51-60$ & 43 \\
\hline Gender & 17 \\
\hline Male & 18 \\
\hline Female & 33 \\
\hline CD4 Counts & 09 \\
\hline$<350$ & \\
\hline $350-500$ & \\
\hline$>500$ & \\
\hline
\end{tabular}

In the present study correlation of etiology with CD4 count shows that papular lesions and dermatitis are the most common lesions seen in patients having CD4 count more than 350 and viral and fungal infections are most common lesions seen in patients having CD4 count less than 350. [Table 2]

In the present study the correlation of Clinical diagnosis with Histopathological findings-an evaluation shows high sensitivity of $88.8 \%$ and specificity of $96.0 \%$ in diagnosis of papular lesions.

High specificity is noted in diagnosis of all the lesions. Thus it has been concluded that histopathological correlation is very important for making the confirm diagnosis and proper treatment of the patient. (Table 3,4$)$. 
Research Article

Table 2: Histopathological and clinical diagnosis of patients: $(n=60)$.

\begin{tabular}{|c|c|c|c|c|c|c|}
\hline \multirow{2}{*}{$\begin{array}{l}\text { Sr. } \\
\text { no. }\end{array}$} & \multirow[t]{2}{*}{ Histopathological and clinical diagnosis } & \multirow{2}{*}{\begin{tabular}{|c|} 
No. of \\
patients $(\%)$
\end{tabular}} & \multirow{2}{*}{$\begin{array}{l}\text { Mean CD4 } \\
\text { count }\end{array}$} & \multicolumn{3}{|c|}{ CD4 count } \\
\hline & & & & $<350$ & $350-500$ & $>500$ \\
\hline 1 & $\begin{array}{c}\text { Dermatitis: Atopic Dermatitis, Ashy dermatitis, } \\
\text { urticaria, Hyperpigmented patch, chronic non- } \\
\text { specific dermatitis }\end{array}$ & $08(13.3)$ & 421.62 & 1 & 6 & 1 \\
\hline 2 & $\begin{array}{l}\text { Papular lesion: Pruritic popular, Psoriasis, } \\
\text { Seborrhoic Dermatitis, Eosinophilic folliculitis, } \\
\text { Scaly lesion, Lichen planus }\end{array}$ & $10(16.6)$ & 428.7 & 0 & 9 & 1 \\
\hline 3 & $\begin{array}{l}\text { Epidermal Lesion:- Epidermoid cyst, Seborrhoic } \\
\text { keratosis }\end{array}$ & $03(5)$ & 438.0 & 0 & 3 & 0 \\
\hline 4 & $\begin{array}{c}\text { Viral lesion:- Warts, Condyloma Lata, } \\
\text { Molluscum contagiosum }\end{array}$ & $07(11.6)$ & 343.28 & 5 & 1 & 1 \\
\hline 5 & $\begin{array}{c}\text { Bacterial infections:-Chanchroid, Hansens, } \\
\text { Tuberculosis verrucosa cutis, Folliculitis, } \\
\text { Pustular lesion, Lupus }\end{array}$ & $08(13.3)$ & 394.5 & 3 & 2 & 3 \\
\hline 6 & $\begin{array}{c}\text { Fungal infections:- Candidiasis, Cryptococcus, } \\
\text { Histoplasma, TineaCorporis }\end{array}$ & $06(10)$ & 144.66 & 6 & 0 & 0 \\
\hline 7 & $\begin{array}{l}\text { Parasitic \&Protozoal infections:- Leishmaniasis, } \\
\text { Scabies }\end{array}$ & $01(1.6)$ & 256.0 & 1 & 0 & 0 \\
\hline 8 & Drug reaction & 0 & - & - & - & - \\
\hline 9 & $\begin{array}{c}\text { Vascular lesion:- Leukocytoclastic vasculitis, } \\
\text { Granuloma Pyogenicum }\end{array}$ & $4(6.6)$ & 427.25 & 0 & 3 & 1 \\
\hline 10 & $\begin{array}{l}\text { Connective tissue lesion:- DLE, Granuloma } \\
\text { Annulare }\end{array}$ & $4(6.6)$ & 422.75 & 0 & 3 & 1 \\
\hline 11 & $\begin{array}{c}\text { Malignant/Premalignant lesion:- Verrucous } \\
\text { Carcinoma, Squamous cell carcinoma, Bowenoid } \\
\text { papulosis }\end{array}$ & $03(5)$ & 273.66 & 2 & 1 & 0 \\
\hline 12 & $\begin{array}{c}\text { Vesiculobullous lesion:- Pemphigus vulgaris, } \\
\text { Bullous pemphigoid, Bullous impetigo, } \\
\text { Erythema Multiforme }\end{array}$ & $4(6.6)$ & 448.25 & 0 & 4 & 0 \\
\hline 13 & $\begin{array}{c}\text { Others:- Follicular keratosis, Perforating } \\
\text { folliculitis }\end{array}$ & $2(3.3)$ & 475.0 & 0 & 1 & 1 \\
\hline & $\begin{array}{c}\text { Total } \\
\end{array}$ & $60(100)$ & 377.01 & 18 & 33 & 9 \\
\hline
\end{tabular}

Table-3: Correlation of clinical diagnosis with histopathological findings - an observation $(\mathbf{n}=60)$.

\begin{tabular}{|c|c|c|c|c|c|c|}
\hline $\begin{array}{c}\text { Sr. } \\
\text { no. }\end{array}$ & Clinical diagnosis & $\begin{array}{c}\text { True } \\
\text { positive }\end{array}$ & $\begin{array}{c}\text { False } \\
\text { Positive }\end{array}$ & $\begin{array}{c}\text { False } \\
\text { negative }\end{array}$ & $\begin{array}{c}\text { True } \\
\text { Negative }\end{array}$ & Total \\
\hline 1 & Dermatitis & 6 & 2 & 5 & 47 & 60 \\
\hline 2 & Popular lesion & 8 & 2 & 1 & 49 & 60 \\
\hline 3 & Epidermal lesion & 2 & 1 & 1 & 56 & 60 \\
\hline 4 & Viral lesion & 7 & 0 & 1 & 52 & 60 \\
\hline 5 & Bacterial lesion & 8 & 0 & 4 & 48 & 60 \\
\hline 6 & Fungal lesion & 5 & 1 & 0 & 54 & 60 \\
\hline 7 & Parasite and Protozoal & 1 & 0 & 0 & 59 & 60 \\
\hline 8 & lesion & - & - & - & - & - \\
\hline 9 & Vrug reaction & 2 & 2 & 0 & 56 & 60 \\
\hline 10 & Connective tissue lesion & 3 & 1 & 1 & 55 & 60 \\
\hline 11 & Malignant/ premalignant & 1 & 2 & 1 & 56 & 60 \\
\hline 12 & Vesiculobullous lesion & 3 & 1 & 1 & & 55 \\
\hline 13 & Others & 1 & 1 & 0 & 58 & 60 \\
\hline
\end{tabular}


Research Article

Table-4: Correlation of clinical diagnosis with histopathological findings - an evaluation $(\mathbf{n}=60)$.

\begin{tabular}{|c|c|c|c|c|c|c|}
\hline Sr. no. & Clinical diagnosis & Sensitivity & Specificity & PPV & NPV & Accuracy \\
\hline 1 & Dermatitis & 54.5 & 95.9 & 75.0 & 90.38 & 88.3 \\
\hline 2 & Popular lesion & 88.8 & 96.0 & 80.0 & 98.0 & 95.0 \\
\hline 3 & Epidermal lesion & 66.6 & 98.2 & 66.6 & 98.2 & 96.6 \\
\hline 4 & Viral lesion & 87.5 & 100 & 100 & 98.1 & 98.3 \\
\hline 5 & Bacterial lesion & 66.6 & 100 & 100 & 92.3 & 93.3 \\
\hline 6 & Fungal lesion & 100 & 98.1 & 83.3 & 100 & 98.3 \\
\hline 7 & $\begin{array}{c}\text { Parasite and } \\
\text { Protozoal lesion }\end{array}$ & 100 & 100 & 100 & 100 & 100 \\
\hline 8 & Drug reaction & - & - & - & - & - \\
\hline 9 & Vascular lesion & 100 & 96.5 & 50.0 & 100 & 96.6 \\
\hline 10 & $\begin{array}{c}\text { Connective tissue } \\
\text { lesion }\end{array}$ & 75.0 & 98.2 & 75.0 & 98.2 & 96.6 \\
\hline 11 & $\begin{array}{c}\text { Malignant / pre- } \\
\text { malignant lesion }\end{array}$ & 50.0 & 96.5 & 33.3 & 98.2 & 95.0 \\
\hline 12 & $\begin{array}{c}\text { Vesiculo-bullous } \\
\text { lesion }\end{array}$ & 75.0 & 98.2 & 75.0 & 98.2 & 96.6 \\
\hline 13 & Others & 100 & 98.3 & 50.0 & 100 & 98.3 \\
\hline
\end{tabular}

PPV- positive predictive value; NPV- negative predictive value

\section{Discussion}

Skin is the most commonly affected organ in HIV. Cutaneous findings in HIV are frequent and include viral, fungal, bacterial and non-infectious etiologies, which not only serve as marker of HIV infection but also a marker of stage of HIV disease. However the morphological pattern of skin lesion in HIV is often non-diagnostic. Histopathological correlation is therefore pivotal in the accurate diagnosis of many HIV induced skin diseases. The study was done to observe the morphological lesions where the confirm clinical diagnosis could not be made and skin biopsies of lesions are taken to do the histopathological confirmation.

In the present study the most affected age group was 21-40 years constituting $74.9 \%$ and a second peak in the age $>40$ years with $24.9 \%$. In study conducted by Nirja jindal et al [7] also showed the same findings with most affected age group was 21-40 years constituting $73.7 \%$ and a second peak in the age group $>40$ years with $21 \%$. In the present study there was male preponderance with 2.5: 1 male to female ratio was seen while different studies reported different rations according to geographic variations. The study done by Nirja Jindal et al [7] showed female preponderance with a ratio of 0.9:1.
In the present study the commonest lesion seen are infectious lesions constituting 36.6\%. Similar observation were found by other authors [7-10]. However in other studies the second most common lesion is Dermatitis followed by papular eruptions whereas in present study second most common lesions are pruritic lesions followed by dermatitis. This difference in the results noted in the present study could have been due to difference in geographical distribution.

In present study mean CD4 cell count was low in individuals with skin infections and malignancy. The study done by Farooq Rad et al [11] shows CD4 cell count higher than that of our study and the study done by Rosemary et al [10] are lower than that of our study. In general, our study showed no strong correlation between CD4 cell counts and skin disorders which could be due to the higher values of CD4 count in our patients. However we concluded that skin disorders can be seen with higher CD4 cell counts in HIV patients. We concluded that skin disorder can be seen with higher CD4 cell counts in HIV patients.

In the present study the correlation of Clinical diagnosis with Histopathological findings-an evaluation shows 
high sensitivity of $88.8 \%$ and specificity of $96.0 \%$ in diagnosis of papular lesions. High specificity is noted in diagnosis of all the lesions. It shows that histopathological correlation is very important for making the confirm diagnosis and proper treatment of the patient [12 - 14].

It has been concluded that the lesions which are most difficult to diagnose clinically are the papular eruptions, followed by dermatitis and bacterial infections. The papular skin lesions include wide variety of lesions for which treatment and prognosis differs, histopathological confirmation is therefore required for proper treatment. Various histopathological diagnosis given after examining the biopsies of these papular lesions are pruritic papular eruption, lichen planus, psoriasis, eosinophilic folliculitis, pustular psoriasis. Common dermatitis found in HIV seropositive patients which are difficult to differentiate clinically are - ashy dermatitis, pustular dermatoses, chronic nonspecific dermatitis, post inflammatory hyperpigmentation. Among the bacterial lesion Hansens, lupus vulgaris, tuberculosis verrucosa cutis, and suppurative folliculitis are common [15-17].

The early and accurate diagnosis of many HIV induced lesions help in guiding the treatment and predicting the prognosis. In our study we have diagnosed seven patients with lepsosy / HIV co-infection. HIV patients concomitantly infected with leprosy may not show any signs of that disease due to diminished cell mediated immunity (CMI) but could be a source of infection to healthy community.

Since most of the clinical signs of leprosy are cell mediated immunity dependant, when HIV positive patient receive the antiretroviral treatment the cell mediated immunity improves and clinical disease manifests. Drastic improvement is seen in these patients when they are started on anti-leprotic treatment along with the anti retroviral treatment [18].

The possibility of adverse drug reaction should always be included in the differential diagnosis of any inflammatory dermatoses in HIV positive patients. Drugs may give rise to variety of histological patterns e.g. lichinoid, spongiotic, pustular, vesiculobullous and urticarial reaction.

Diagnostic approach: - The approach to HIV positive skin biopsies
- Do the broad categorization of major histological reaction pattern with subsequent interpretation in context of presenting clinical symptoms/signs and approximate clinical differentiation.

- Unless the diagnosis is obvious on H\&E sections careful examination of multiple serial sections should always be undertaken.

- Multiple biopsies should always be recommended if there is any clinical suspicion of multiple disease process.

\section{Conclusion}

The most common type of skin lesions in HIV patients are papular lesions followed by dermatitis and bacterial infections. No strong correlation was found between CD4 count and skin manifestations. In the present study out of 60 cases, it has been concluded that the morphological pattern of skin lesion in HIV is often non- diagnostic probably because HIV must have altered the clinical presentation.

Histopathological correlation is therefore pivotal in the accurate diagnosis of many HIV induced skin diseases. The histopathological examination of such lesions helps in confirming the diagnosis as they have high sensitivity and specificity values.

Funding: Nil, Conflict of interest: None initiated, Permission from IRB: Yes

\section{References}

1. Bunker CB, Gotch F. Rook's Text book of dermatology. 2nd ed. Oxford: Blackwell Scientific; 2004.

2. UNAIDS. Report on global AIDS epidemic July; 2004.

3. Park AG. Text book of preventive and social medicine. 7th ed. JP publication; 2007.

4. Grayson W. The HIV-positive skin biopsy. J Clin Pathol. 2008 Jul;61(7):802-17. Epub 2007 Nov 15.

5. Coldiron BM, Bergstresser PR. Prevalence and clinical spectrum of skin disease in patients infected with human immunodeficiency virus. Archives of dermatology. 1989 Mar 1;125(3):357-61. 


\section{Research Article}

6. Tschachler E, Bergstresser PR, Stingl G. HIV-related skin diseases. Lancet. 1996 Sep 7; 348 (9028):659-63.

7. Jindal N, Aggarwal A, Kaur S. HIV seroprevalence and HIV associated dermatoses among patients presenting with skin and mucocutaneous disorders. Indian Journal of Dermatology, Venereology, and Leprology. 2009 May 1;75(3):283.

8. Kumarasamy N, Vallabhaneni S, Flanigan TP, Mayer $\mathrm{KH}$, Solomon S. Clinical profile of HIV in India. Indian J Med Res. 2005 Apr;121(4):377-94.

9. Wiwanitkit V. Prevalence of dermatological disorders in Thai HIV infected patients correlated with different CD4 lymphocyte count statuses: A note on 120 cases. Int J Dermatol. 2004;43:265-8.

10. Spira R, Mignard M, Doutre MS, Morlat P, Dabis F. Prevalence of cutaneous disorders in a population of HIV-infected patients: southwestern France, 1996. Arch Dermatol. 1998 Oct 1;134(10):1208-12.

11. Rad F, Ghadheri E. Relationship between skin manifestations and CD4 count among HIV positive patients. Pakistani Journal of medical sciences.2008; 24:114-117.

12. NACO. National AIDS Control Organization Annual Report. New Delhi, India; 2007.
13. Supanaranond W, Desakorn V, Sitakalin C, Naing $\mathrm{N}$, Chirachankul P. Cutaneous manifestations in HIV positive patients. Southeast Asian J Trop Med Public Health. 2001 Mar;32(1):171-6.

14. Hevia O, Jimenez-Acosta F, Ceballos PI, Gould EW, Penneys NS. Pruritic papular eruption of the acquired immunodeficiency syndrome: a clinicopathologic study. J Am Acad Dermatol. 1991 Feb; 24 (2 Pt 1): 231-5.

15. Rosenthal D, LeBoit PE, Klumpp L, Berger TG. Human immunodeficiency virus-associated eosinophilic folliculitis. A unique dermatosis associated with advanced human immunodeficiency virus infection. Arch Dermatol. 1991 Feb;127(2):206-9.

16. Nichols L, Balogh K, Silverman M. Bacterial infections in the acquired immune deficiency syndrome. Clinicopathologic correlations in a series of autopsy cases. Am J Clin Pathol. 1989;92:787-90.

17. Dover JS, Johnson RA. Cutaneous manifestations of human immunodeficiency virus infection. Part II. Arch Dermatol. 1991 Oct;127(10):1549-58.

18. Vasudevan B, Sagar A, Bahal A, Brig AP, Mohanty VS. Cutaneous manifestations of HIV - A detailed study of morphological variants, markers of advanced disease, and the changing spectrum. Med J Armed Forces India. 2012;68:20-7.

\section{How to cite this article?}

Goswami D, Rayal A, Jadav M. Histopathogical study of dermatological lesions in HIV reactive patients. Trop J Path Micro 2017;3(2):107-113.doi: 10.17511/jopm.2017.i2.05. 